\title{
Dossier: Teoría de la Historia e Historia de la Historiografía en América Latina y el Caribe
}

\section{Coordinadores: \\ Fabio Wasserman (instituto Ravignani, Universidad de Buenos Aires - Conicet) Jurandir Malerba (PPG História UFRGS)}

La constitución de la historia como disciplina en América Latina y el Caribe durante los siglos XIX y XX coincidió con el proceso de emergencia y consolidación de los Estados nacionales a los que proveyó de relatos e interpretaciones sobre sus orígenes, su evolución, sus rasgos particulares y su identidad. De ese modo, las narrativas históricas tomaron a la nación como principal escala de análisis y, mucho más importante aún, como sujeto protagónico de los procesos históricos.

Hasta mediados del siglo $\mathrm{XX}, \mathrm{y}$ aunque con importantes diferencias regionales, la historiografía de los países latinoamericanos se desarrolló en buena medida por fuera de los sistemas universitarios. Los historiadores eran en general políticos, funcionarios, escritores, médicos o abogados, que podían estar ligados o no a instituciones como las academias de historia, los institutos históricos o las sociedades de estudios históricos. Después de la Segunda Guerra Mundial, y sobre todo a partir de la década de 1960 , las universidades comenzaron a concentrar la producción de conocimiento histórico. Tributaria de una tradición local de ensayismo crítico, y enriquecida por el contacto con la historia social marxista y annaliste -contacto que en parte se debió al exilio provocado por las dictaduras militares-, la historiografía latinoamericana fue entonces objeto de una notable renovación teórico-metodológica que promovió la incorporación de nuevos temas, problemas y abordajes. En 
ese sentido se destaca la consideración de América Latina y el Caribe como un espacio con una historia común que era pensada con categorías como dependencia, desarrollo, modernización o formación económico-social. Sin embargo, y a diferencia de lo sucedido con otras disciplinas como la filosofía, la sociología - la economía, esta caracterización no fue una condición suficiente para que la historiografía produjera interpretaciones y narraciones de conjunto capaces de trascender la suma de casos nacionales.

A partir de la década de 1980 comenzó a producirse un proceso de expansión y de diversificación temática en la historiografía de los países latinoamericanos. Una de las razones de estos cambios fue la progresiva internacionalización de la vida académica, favorecida por la estandarización de la formación en el grado y el posgrado, y por la circulación de investigadores, docentes y estudiantes, tanto a nivel continental como internacional. En ese marco se fue produciendo una creciente especialización y se hicieran más frecuentes los estudios que utilizan escalas de análisis subnacionales, ya sean regiones, provincias o ciudades. Durante la década de 1990, por su parte, los procesos de globalización pusieron en cuestión a las historias nacionales como marco interpretativo de los procesos históricos. De ese modo, y a pesar de que aún siguen teniendo un peso significativo las instituciones $y$ las tradiciones intelectuales nacionales, y de que el formato historia nacional continúa siendo el predominante, se advierte un importante movimiento de renovación teórica que, con diversa presencia en todo el continente, dio un nuevo aire al debate y a la producción de conocimiento histórico al incorporar sujetos, perspectivas y formas narrativas que cuestionan el nacionalismo historiográfico.

Esta descripción breve y esquemática no implica desconocer que los autores de las historias nacionales de los países latinoamericanos entendían -y entienden- que las mismas forman parte de procesos más amplios de alcance regional, continental, occidental o global. Lo cierto, sin embargo, es que 
cuando se procura realizar empresas que toman a América Latina y el Caribe como objeto, lo que suele ocurrir es que se reúnen trabajos de distintos autores sobre casos nacionales, evidenciando así que los historiadores latinoamericanos somos, ante todo, historiadores nacionales. No sucede lo mismo en el sistema académico europeo y norteamericano, en los que durante el siglo XX se fue conformando una tradición de estudios latinoamericanistas. De este contraste resulta ilustrativa la intervención de Hilda Sabato al clausurar el XVII Congreso Internacional de Ahila -Asociación de Historiadores Latinoamericanistas Europeos-realizado en Berlín en septiembre de 2014. En una conferencia dedicada a reflexionar sobre las distintas formas en las que se abordó la historia de América Latina, la historiadora argentina recordaba que al llegar a Londres a mediados de la década de 1970 para realizar un doctorado, descubrió con sorpresa que era considerada por sus colegas como una "latinoamericanista", categoría que hasta entonces desconocía por completo (SABATO 2015, p. 138).

La historia de la historiografía de los países latinoamericanos acompañó el movimiento general de la disciplina al enfocarse en documentar y examinar el proceso de constitución de cada historiografía nacional. Los estudios sobre teoría de la historia, por su parte, suelen tener un carácter general o procuran examinar la recepción de corrientes o teorías y su aporte en la conformación de un campo disciplinar e institucional nacional. De ahí la escasez de una tradición de indagaciones en el campo de la teoría e historia de la historiografía que consideren en conjunto a América Latina y el Caribe, y que entre esos escasos estudios se destaquen los realizados por investigadores europeos y estadounidenses (STEIN 1964; MÖRNER 1973). Este estado de cosas comenzó a cambiar en las últimas dos décadas con la publicación de estudios comparativos y visiones de conjunto (GUERRA VILABOY 2003; MALERBA 2010; SOSA y CONNAUGHTON 1999). Una novedad en ese sentido es la inclusión de la historia de la historiografía latinoamericana en algunas colecciones de historia de la historiografía mundial (MACINTYRE; MAIGUASHCA; PÓK 2011) o de historia de 
América Latina (REZENDE MARTINS; PÉREZ BRIGNOLI 2006). Además de estas aproximaciones generales, también puede advertirse una creciente proliferación de balances, estados de la cuestión y estudios historiográficos sobre temas y problemas que, ya sea por la acumulación de conocimiento o por la escala de análisis utilizada por los investigadores, trascienden las historias nacionales, tal como sucede con la historiografía de los procesos revolucionarios e independentistas (CHUST; SERRANO 2007). No parece casual que uno de los temas en los que más se haya avanzado en ese sentido, sea el examen de los procesos de creación de las historias nacionales a lo largo del siglo XIX, movimiento que puede considerarse como un intento por repensar las bases a partir de la cual se constituyeron las historiografías nacionales (COLMENARES 1986; DEVOTO 2008; MEJÍA 2009; PALACIOS 2009; SANSÓN CORBO, 2015).

Este Dossier fue concebido como un aporte al establecimiento de una agenda para la Teoría de la Historia y la Historia de la Historiografía en América Latina y el Caribe. En ese sentido, y dado que el estado actual del conocimiento en este campo es fragmentario, parcial y con importantes vacíos, más que ofrecer interpretaciones totales o acabadas, nos propusimos dar lugar a estudios que trasciendan los casos nacionales o que sólo sean un agregado de los mismos, ya sea que reflexionen o se interroguen sobre los fundamentos de nuestras historiografías, ofrezcan una mirada de conjunto, utilicen un enfoque comparativo, o realicen un examen sobre circulación, vínculos y contactos.

El Dossier se inicia con un ensayo de Elías Palti, El tópico de "los orígenes ideológicos" de las revoluciones de independencia como problema, que durante mucho tiempo constituyó uno de los temas centrales en la historia de las ideas y del pensamiento latinoamericano. En ese sentido destaca la ruptura que implicó el libro Tradición política española e ideología revolucionaria de Mayo publicado en 1961 por el historiador argentino Tulio Halperin Donghi, ya que puso en cuestión la forma en la que se planteaba el análisis del discurso revolucionario a partir de 
la filiación de las ideas que lo informaban. A través de una relectura de este clásico de la historiografía latinoamericana, Palti propone un esbozo de las torsiones que sufrieron algunos conceptos clave del pensamiento tradicional hispano y cómo a partir de estos pudo emerger el discurso revolucionario hispanoamericano.

En el siguiente texto, A história intelectual e a história da historiografia latino-americana: internalismo, externalismo e mediação nas análises de Facundo, Fabiula Sevilha propone un diálogo entre la historia de la historiografía y una renovada historia intelectual. En ese sentido plantea la necesidad de desarrollar una estrategia de análisis crítico que articule tanto un abordaje "internalista" como uno "externalista", vale decir, que sea capaz de considerar tanto la estructura y composición de las obras como sus condiciones de producción. Para explorar las posibilidades de esta articulación, analiza la forma en la que Oscar Terán y Carlos Altamirano abordaron un texto clásico del siglo XIX iberoamericano, el Facundo (1845) de Domingo F. Sarmiento.

En Varnhagen, Santarém e Avezac: um episódio da polêmica vespuciana (1842-1858), Daniel Estudante Protásio trata un problema que cruza la historiografía europea y la americana desde el siglo XVI hasta el presente: las discusiones sobre la autenticidad de los relatos de los viajes realizados por Américo Vespucio. El trabajo se centra en la obra, la correspondencia y la pertenencia institucional de tres historiadores y geógrafos de mediados del siglo XIX, Santarém, Varnhagen y Avezac, haciendo foco en las discusiones que sostuvieron y en los planteos metodológicos utilizados para determinar la autenticidad de los textos vespucianos.

Martha Rodríguez, por su parte, nos presenta en De historiadores y de los posibles usos de su saber. La contribución de los Congresos Internacionales de Historia de América en la conformación de una identidad americana (1930-1960), un fenómeno poco tratado a pesar de su gran interés: los congresos internacionales de historia de América. El trabajo 
se centra en los congresos realizados en Buenos Aires en las décadas centrales del siglo XX. Además de reconstruir cómo se realizaron, quiénes participaron y los temas tratados, la autora llama la atención sobre su impacto más allá del campo académico al contribuir a establecer algunos sentidos sobre la identidad americana, sobre el pasado y el futuro del continente y sobre su papel en las relaciones internacionales.

En Uma poética da relação: a conversa infinita entre Édouard Glissant e Michel Leiris, Gabriela Theophilo nos recuerda algo que muchas veces solemos olvidar: cuando nos referimos a América Latina también lo estamos haciendo al Caribe. Asimismo plantea el problema de si es posible entender el desarrollo de la historiografía y de las ciencias sociales latinoamericanas y caribeñas sin tener en cuenta su relación con Europa y la construcción de categorías de análisis específicas. En ese sentido, el trabajo examina cómo el etnógrafo antillano Édouard Glissant elaboró y utilizó algunas categorías de análisis como "créolisation" y "relation" a partir del diálogo que mantuvo con la obra del escritor y etnólogo francés Michel Leiris, que a mediados del siglo XX había sido enviado por la Unesco a las Antillas para estudiar las relaciones interétnicas.

El Dossier se cierra con Tiempo, historia y política. Una reflexión comparativa sobre las conmemoraciones bicentenarias en México y Argentina, un trabajo en el que Camila Perochena examina comparativamente las recientes conmemoraciones oficiales de los procesos revolucionarios e independentistas en países gobernados por fuerzas políticas de distinto signo ideológico. El trabajo muestra que mientras que en México primó la intención de construir una memoria conciliatoria del pasado y del presente, en Argentina se remarcaron las rupturas y las divergencias. De ese modo, se habrían constituido dos representaciones diferentes de la idea de revolución, pero también de las relaciones entre pasado, presente y futuro.

Como podrá advertirse, estos textos, al igual que los de Nicolás Lavagnino y Nuria Muñoz que también se publican en este número de História da Historiografia, proponen diversos 
temas, abordajes, periodizaciones y escalas de análisis. Esta diversidad es tan sólo una muestra del potencial que tiene la ampliación de la indagación historiográfica más allá de las historias nacionales. Que este potencial se transforme en una realidad dependerá de nuestra capacidad para dar forma a una historiografía y a una teoría e historia de la historiografía de América Latina y el Caribe que, interesada en el pasado, presente y futuro de la región, logre estar a la altura de los desafíos que ésta debe enfrentar.

\section{BIBLIOGRAFIA}

COLMENARES, Germán. Las convenciones contra la cultura. Ensayos sobre historiografía hispanoamericana del siglo XIX. Bogotá: Tercer Mundo Editores, 1986.

CHUST, Manuel; SERRANO, José Antonio (eds.). Debates sobre las independencias iberoamericanas. Madrid/ Iberoamerica Editorial Vervuert, 2007.

DEVOTO, Fernando. La construcción del relato de los orígenes en Argentina, Brasil y Uruguay: las historias de Varnhagen, Mitre y Bauzá. In: ALTAMIRANO, Carlos (dir.) Historia de los intelectuales en América Latina. vol I. MYERS, Jorge (ed.) La ciudad letrada, de la conquista al modernismo. Buenos Aires: Katz editores, 2008, p. 269-289.

GUERRA VILABOY. Las grandes corrientes de la historiografía latinoamericana. Clío, n 166, p. 145-182, 2003.

MACINTYRE, Stuart; MAIGUASHCA, Juan; PÓK, Attila (eds.). The Oxford History of Historical Writing. Vol. 4: 18001945. New York y Oxford: Oxford University Press, 2011.

MALERBA, Jurandir. La historia en América Latina. Ensayo de crítica historiográfica. Rosario: Prohistoria ediciones, 2010. 
MEJÍA MACÍA, Sergio. La noción de historicismo americano y el estudio de las culturas escritas americanas. Historia Crítica, n 39, p. 246-260, 2009.

MÖRNER, Magnus. The study of Latin American History today. Latin American Research Review, 8 (2), p. 7593, 1973.

PALACIOS, Guillermo (coord.). La nación y su historia. Independencias, relato historiográfico y debates sobre la nación en América Latina. México: El Colegio de México, 2009.

REZENDE MARTINS, Estevão de; PÉREZ BRIGNOLI, Héctor (dirs.). Historia general de América Latina. Teoría y metodología de la Historia de América Latina. Vol. IX. Madrid: UNESCO, 2006.

SABATO, Hilda. Historia latinoamericana, historia de América Latina, Latinoamérica en la historia. Prismas, Revista de historia intelectual, n 19, p. 135-145, 2015.

SANSÓN CORBO, Tomás. Introducción. Notas para una historia de la historiografía latinoamericana en el siglo XIX. Anuario del Instituto de Historia Argentina, n 15, p. 1-5, 2015.

SOSA, Ignacio; CONNAUGHTON, Brian F. (coords.). Historiografía Latinoamericana Contemporánea. México: Universidad Nacional Autónoma de México, 1999.

STEIN, Stanley. Historiografía latinoamericana. Balances y perspectivas. Historia Mexicana, 14 (1), p. 1-41, 1964 